\title{
Karyology of Rhodeus amarus (Block, 1782) (Teleostei, Acheilognathidae) from Turkey
}

\section{Muradiye Karasu Ayata ${ }^{1, *}\left(\mathbb{D}\right.$, Sevgi Ünal Karakuş ${ }^{2}$, Muhammet Gaffaroğlu ${ }^{3}$}

\author{
${ }^{1}$ Kırşehir Ahi Evran University, Faculty of Health Sciences, Kırşehir, Turkey. \\ ${ }^{2}$ Bartın University, Faculty of Science, Department of Molecular Biology and Genetics, Bartın, Turkey. \\ ${ }^{3}$ Kırşehir Ahi Evran University, Faculty of Science and Art, Department of Molecular Biology and Genetics, Kırşehir, \\ Turkey.
}

\section{Article History}

Received 07 December 2020

Accepted 25 Januray 2021

First Online 09 February 2021

\section{Corresponding Author \\ Tel.: +908504410244 \\ E-mail: mkarasu@ahievran.edu.tr}

\section{Keywords}

Chromosome

Karyotype

C-banding

Ag-NOR

\begin{abstract}
The aim of this study was to determine chromosomal characteristics of Rhodeus amarus (Block, 1782) from Turkey by conventional procedures (Giemsa, C-banding and Ag-NOR staining). Metaphase chromosomes were obtained from the head kidney cells. The diploid number was found as 48 and the fundamental number as 76 . Chromosomes were morphologically characterized as metacentric (four pairs), submetacentric (10 pairs) and subtelo-acrocentric (10 pairs). C-bands were found to occur on the pericentromeric regions of most of the chromosomes and a single $\mathrm{Ag}$ NOR was observed on Silver stained metaphases. The results may expand the knowledge on chromosomal features of bitterlings.
\end{abstract}

\section{Introduction}

The genus Rhodeus Agassiz, 1832 belonging to the family Acheilognathidae has 23 valid species in the inland waters of Eurasia (Froese \& Pauly, 2020). R. amarus, known as European bitterling, is a small freshwater fish inhabiting lakes and slow flowing rivers (Froese \& Pauly, 2020), and is also distributed in inland waters of Turkey (ilhan, Sarı, \& Ekmekçi, 2014). Although abundant in most of its distribution range, $R$. amarus is threatened by environmental changes like water pollution due to anthropogenic action (Kirtiklis, Ocalewicz, Wiechowska, Boron, \& Hliwa, 2014).

The members of Rhodeus like other bitterlings show an unusual spawning symbiosis with freshwater mussels. Rhodeus females develop long ovipositors that they use to place their eggs onto the gills of a mussel through an exhalant siphon. Males fertilize the eggs by releasing sperm into the inhalant siphon of the mussel and embryos develop inside the mussel about a month. Then, embryos leave the mussel as actively swimming larvae. This reproduction relationship of Rhodeus with mussels makes it a very attractive material in different scientific studies (Smith, Reichard, Jurajda, \& Przybylski, 2004).

Cytogenetic characters are important tools for many scientific purposes (Kirtiklis et al., 2014). In Turkey, freshwater fish chromosomal studies have been increased after 2003 (Gaffaroğlu, 2003), although often limited to the determination of the diploid number (2n), fundamental arm number (FN) and chromosome morphology (Gaffaroğlu, Yüksel, \& Rab, 2006; Ayata, Yüksel, \& Gaffaroğlu, 2016; Unal \& Gaffaroğlu, 2016), in addition to C-banding and Silver staining methods (Gaffaroğlu et al., 2006; Ayata et al., 2016; Unal \& Gaffaroğlu, 2016; Ayata, Yüksel, \& Gaffaroğlu, 2019). 
Chromosomal studies in $R$. amarus from European localities (Libertini et al., 2008; Kirtiklis et al., 2014) have been reported before. However, there are no chromosomal reports for $R$. amarus from the inland waters of Turkey. Thus, the main goal of the present study was to determine some chromosomal characteristics of this species from Turkey for the first time.

\section{Material and Methods}

Three specimens (1 female, 2 males) were collected from Dibekdere, Ahmetli, Manisa $\left(38^{\circ} 33^{\prime} \mathrm{N}\right.$, $27^{\circ} 57^{\prime} \mathrm{E}$ ). The specimens were carried alive to laboratory and kept in well-aerated aquarium until the analysis. Chromosomal preparations were obtained from the head kidney cells according to the air-drying technique of Bertollo, Cioffi, \& Moreira-Filho (2015). At least 10 slides were prepared from each individual. Some slides were stained by $5 \%$ Giemsa solution. The C-banding technique of Sumner (1972) was used for visualization of constitutive heterochromatin regions, whereas the Silver staining technique of Howell \& Black (1980) was followed for determining Ag-NORs. Slides were screened in Leica DM 3000 microscope (Leica Microsystems GmbH, Germany). Photographs of metaphases were taken with AKAS software (Argenit Mikrosistem, Turkey). At least 100 metaphases were examined for determining the $2 n$ number. Karyotypes were manually arranged and chromosomes classified according to Levan, Fredga, \& Sandberg, (1964). For calculating the FN, meta- and submetacentric chromosomes were taken as biarmed, whereas subteloacrocentric chromosomes were taken as uniarmed. Image processing was performed in Adobe Photoshop CS6.

\section{Results and Discussion}

The diploid number of $R$. amarus was invariably $2 n=48$ (Figure $1 \mathrm{~A}$ ). Chromosomes were morphologically characterized as metacentric (four pairs), submetacentric (10 pairs) and subtelo-acrocentric (10 pairs) (Figure 1B). The FN was calculated as 76 both in males and female, and heteromorphic sex chromosomes were not detected in this species. Cbands were found to occur in the pericentromeric region of most chromosomes (Figure $2 \mathrm{~A}$ ) and Ag-NORs in the terminal region of short arms of one submetacentric pair (Figure 2B).

Our data confirm the karyological conservativeness of $2 n=48$, which has been suggested as a basal characteristic for Acheilognathinae (Arai \& Akai, 1988). Accordingly, the $2 \mathrm{n}$ and $\mathrm{FN}$ numbers and the chromosomal morphologies of $R$. amarus from Turkey are the same as those of other European populations (Libertini et al., 2008; Kirtiklis et al., 2014). However, as these are the first data from $R$. amarus from Turkey, other populations deserve to be investigated for a more detailed comparison between European and Anatolian populations.

Otherwise, the diploid number varies from 46 to 48 among Rhodeus species (Ueda et al., 2001). In R. amarus the chromosomal number and morphology are the same as those found in $R$. lighti (Ueda et al., 1997), $R$. sinensis, R. ocellatus (Ueda, Naoi, \& Arai, 2001), $R$. kurumeus (Sola et al., 2003), and R. uyekii (Gil et al., 2016). Consequently, there is no difference among the karyotypes of the above-mentioned species, pointing to conservatism along the karyotype evolution of the Rhodeus genus. Indeed, $R$. fangi is the only divergent species concerning the diploid number $(2 n=46), F N$ and chromosomal morphology, suggesting that these

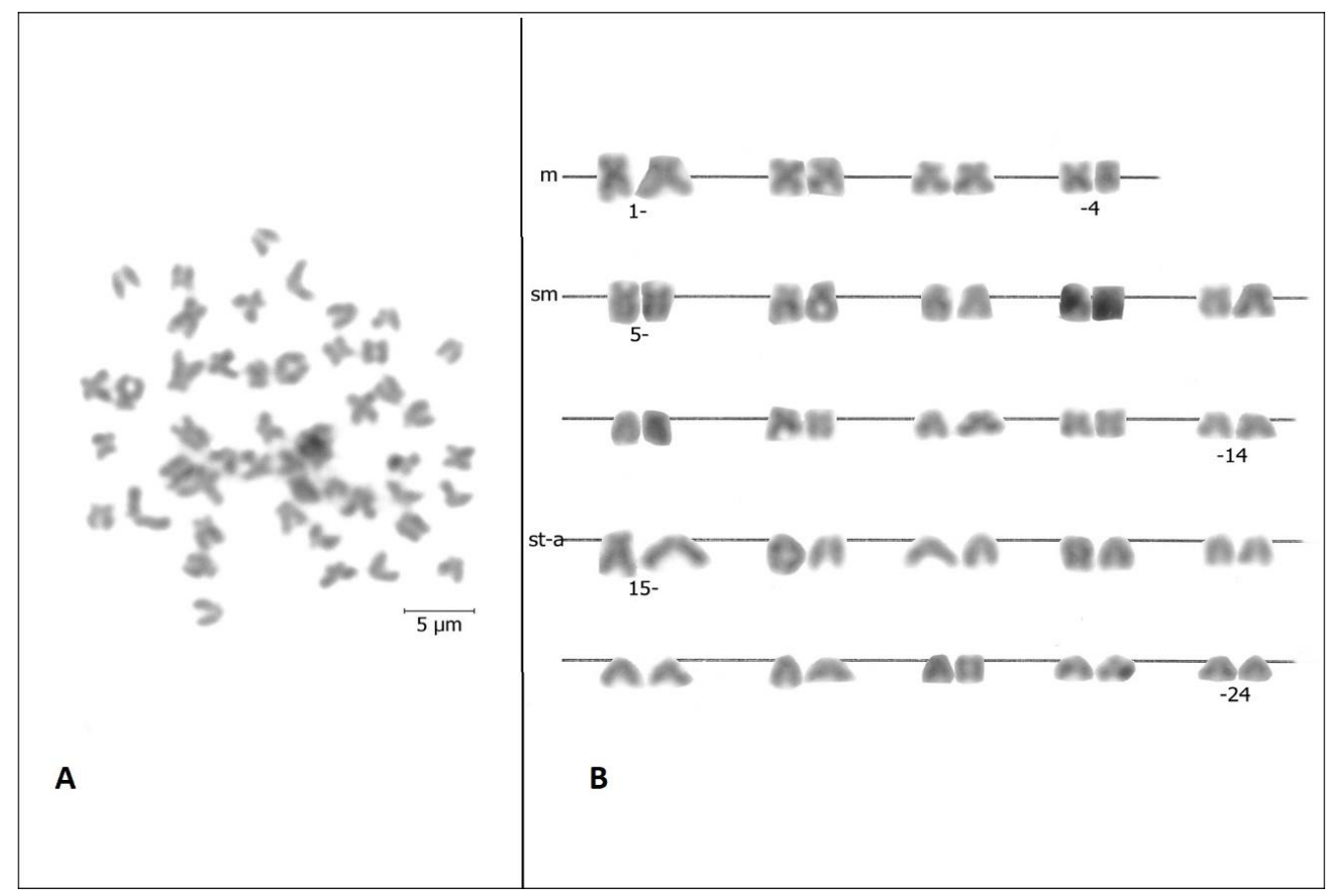

Figure 1. Giemsa stained metaphase (A) and the relative karyotype (B) of Rhodeus amarus. Scale bar $=5 \mu \mathrm{m}$. 


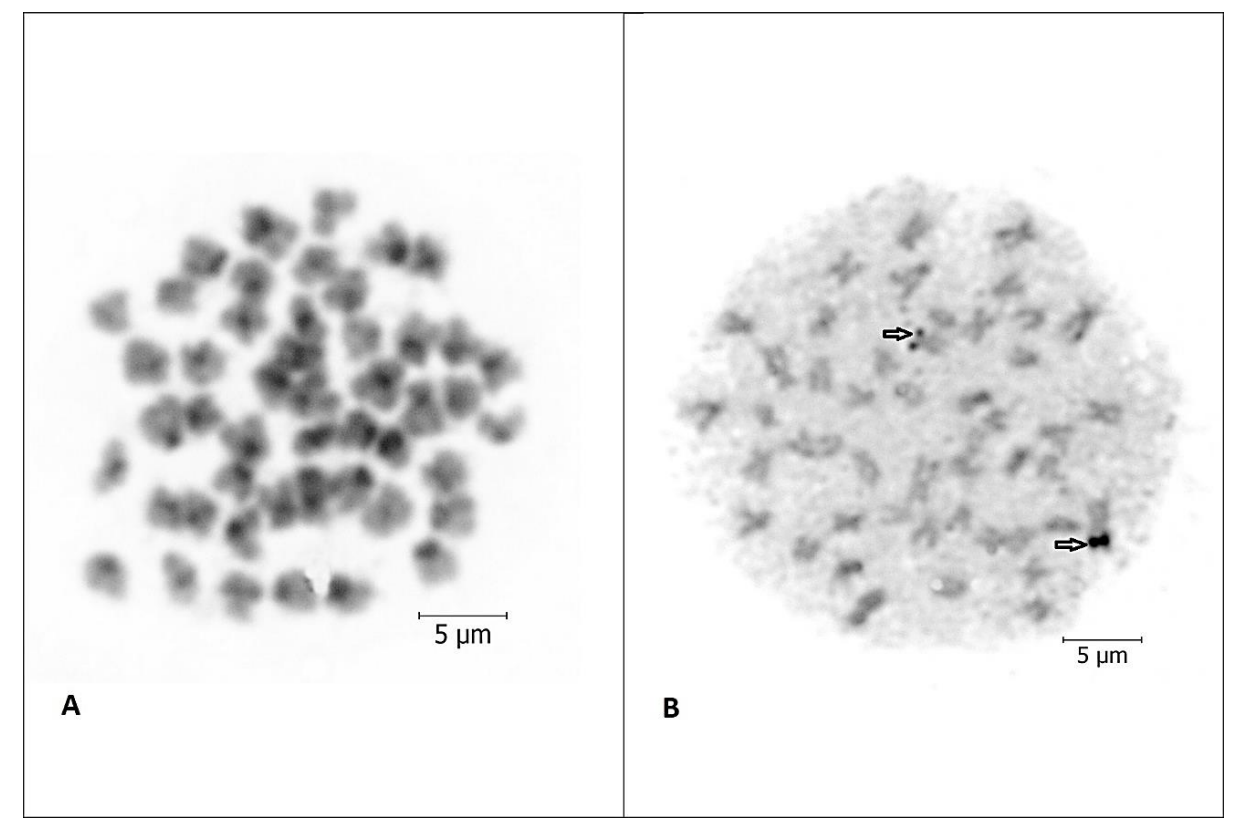

Figure 2. C-banded metaphase (A) and Silver stained metaphase (B) of Rhodeus amarus. Arrows indicate the Ag-NORs. Note a polymorphism in size between the homologous NORs. Scale bar $=5 \mu \mathrm{m}$.

species features are derived by pericentric inversions and tandem fusions (Ueda et al., 2001).

Heteromorphic sex chromosomes are known only in a restricted group of fish species (Arai, 2011). In $R$. amarus they are also not differentiated, both in the present as in other analyzed populations (Libertini et al., 2008; Kirtiklis et al., 2014). Likewise, other Rhodeus species, such as $R$. lighti (Ueda et al., 1997), R. fangi, $R$. sinensis, $R$. ocellatus (Ueda et al., 2001) and $R$. kurumeus (Sola et al., 2003) do not hold such a characteristic in their karyotypes.

Kirtiklis et al. (2014) reported that the pericentromeric regions of most or even all chromosomes are composed of constitutive heterochromatin in bitterlings, as evidenced by their Cband patterns. The $\mathrm{C}$-band pattern of $R$. amarus now investigated is similar to that of $R$ amarus from Poland and other Rhodeus species, such as $R$. fangi, $R$. sinensis, $R$. ocellatus (Ueda et al., 2001) and $R$. kurumeus (Sola et al., 2003). Thus, it is likely that constitutive heterochromatin acts as an important genetic component on the karyotype evolution of bitterlings (Ueda et al., 2001).

In turn, the nucleolar organizing regions are not as conservative as the C-bands among Rhodeus species. Kirtiklis et al. (2014) report that a single pair of chromosomes carrying Ag-NORs appears to be the main pattern among bitterling species. However, despite this, Libertini et al. (2008) consider that Ag-NORs variability is also a common feature in Rhodeus, as a consequence of rDNA rearrangements, including the numerical polymorphism as found in $R$. amarus from northern Italy. The number and location of the Ag-NORs in the sample now investigated are the same as those found in some other European populations (Libertini et al., 2008; Kirtiklis et al., 2014), but differing in chromosomal location with $R$. ocellatus (Ueda et al., 2001) and $R$. uyekii (Gil et al., 2016). In turn, the number of the AgNORs of $R$. amarus differs from those in $R$. lighti (Ueda et al., 1997), $R$. fangi and $R$. sinensis (Ueda et al., 2001). In addition, the polymorphism found in $R$. amarus from Poland (Kirtiklis et al., 2014) is also observed between the homologous carrying the Ag-NORs in the present study.

In conclusion, this study reports the chromosomal characteristics of $R$. amarus from Turkey for the first time. Although samples from a single population have so far been investigated, it was characterized that the population now analyzed has similarities, but also disagreements with other $R$. amarus populations, as well as with other Rhodeus species. Therefore, the results expand the knowledge of the evolutionary process of this particular species of Acheilognathidae, as well as of the genus Rhodeus as a whole.

\section{Ethical Statement}

All applications related to fish were carried out in accordance with the permission of the Kırşehir Ahi Evran University Local Ethics Committee for Animal Experiment (permit number: 68429034/09).

\section{Funding Information}

There is no financial support for this study.

\section{Author Contribution}

MKA collected the specimens, performed the laboratory work and wrote the manuscript; SUK performed the laboratory work and reviewed the manuscript; MG provided critical comments about the 
study, arranged the karyotype and final approval of the manuscript.

\section{Conflict of Interest} interest.

The authors declare that there is no conflict of

\section{Acknowledgements}

The authors are grateful to Ali AYATA and Yalçın KARASU for helping in the field. Our special thanks to the anonymous reviewers for their valuable contribution on the manuscript.

\section{References}

Arai, R. 2011. Fish karyotypes. A Check List. Springer, Japan, pp: 1-10.

Arai, R., \& Akai, Y. 1988. Acheilognathus melanogaster, a senior synonym of $A$. moriokae, with a revision of the genera of the subfamily Acheilognathinae (Cypriniformes, Cyprinidae). Bulletin of the National Science Museum, 14: 199-213.

Ayata, M.K., Yüksel, E. \& Gaffaroğlu, M. 2016. Cytogenetic studies on six species of the leuciscine genus Pseudophoxinus Bleeker, 1860 (Teleostei, Cyprinidae). Caryologia, 69(3), 215-222. http://doi: 10.1080/00087114.2016.1169089.

Ayata, M.K., Yüksel, E. \& Gaffaroğlu, M. 2019. Ag-NOR Karyotypes of five endemic Pseudophoxinus Bleeker, 1860 (Teleostei: Leuciscidae) species from Anatolia. Genetics of Aquatic Organisms, 3(1), 27-30. http://doi.org/10.4194/2459-1831-v3_1_04.

Bertollo, L.A.C., Cioffi, M.B., \& Moreira-Filho, O. 2015. Direct chromosome preparation from freshwater teleost fishes. In: Fish cytogenetic techniques, ray-fin fishes and chondrichthyans. Eds: Ozouf-Costaz, C., Pisano, E., Foresti, F., \& Toledo, L.F.A. CRC Press, USA, pp: 21-26.

Froese, R. \& Pauly, D. 2020. FishBase. http://www.fishbase.org. Accessed 23.11.2020 https://www.fishbase.in/Nomenclature/ScientificName SearchList.php?

Gaffaroğlu, M. 2003. The caryological analysis of some species from Cyprinidae in Karakaya dam lake, PhD Thesis, İnönü University, Malatya, Turkey. (In Turkish).

Gaffaroğlu, M., Yüksel, E. \& Rab, P. 2006. Note on the karyotype and NOR phenotype of leuciscine fish Acanthobrama marmid (Osteichthyes, Cyprinidae). Biologia, 61(2), 207-209. http://doi: 10.2478/s11756006-0031-y.
Gil, H.W., Kong, H.J., An, C.M., Kim, B.S., Lim, S.G. \& Park, I.S. 2016. Cytogenetic study of diploid and tetraploid in Korean rose bitterling, Rhodeus uyekii. SpringerPlus, 5(186), 1-10. http://doi: 10.1186/s40064-016-1830-4.

Howell, W.M. \& Black, D.A. 1980. Controlled silver-staining of nucleolus organizer regions with a protective colloidal developer: a 1-step method. Experientia, 36, 1014-1015.

IIlhan, A., Sarı, H. M. \& Ekmekçi, B. 2014. The length-weight relationship of bitterling, Rhodeus amarus (Bloch, 1782) in freshwaters of Turkey. Journal of FisheriesSciences.com, 8(3), 181-185. http://doi: 10.3153/jfscom.201422.

Kirtiklis, L., Ocalewicz, K., Wiechowska, M., Boron, A. \& Hliwa, P. 2014. Molecular cytogenetic study of the European bitterling Rhodeus amarus (Teleostei: Cyprinidae: Acheilognathinae). Genetica, 142, 141-148. http://doi: 10.1007/s10709-014-9761-x.

Levan, A., Fredga, K. \& Sandberg, A.A. 1964. Nomenclature for centromeric position on chromosomes. Hereditas, 52, 201-220.

Libertini, A., Sola, L., Rampin, M., Rossi, A.R., lijima, K. \& Ueda, T. 2008. Classical and molecular cytogenetic characterization of allochthonous European bitterling Rhodeus amarus (Cyprinidae, Acheilognathinae) from Northern Italy, Genes and Genetic Systems, 83, 417-422.

Smith, C., Reichard, M., Jurajda, P. \& Przybylski, M. 2004. The reproductive ecology of the European bitterling (Rhodeus sericeus). Journal of Zoology, 262, 107-124 http://dx.doi.org/10.1017/S0952836903004497.

Sola, L., Gornung, E., Naoi, H., Gunji, R., Sato, C., Kawamura, K., Arai, R. \& Ueda, T. 2003. FISH-mapping of 18 S ribosomal RNA genes and telomeric sequences in the Japanese bitterlings Rhodeus ocellatus kurumeus and Tanakia limbata (Pisces, Cyprinidae) reveals significant cytogenetic differences in morphologically similar karyotypes. Genetica, 119, 99-106.

Sumner, A.T. 1972. A simple technique for demonstrating centromeric heterochromatin. Experimental Cell Research, 75, 304-306.

Ueda, T., Mashiko, N., Takizawa, H., Akai, Y., İshinabe, T., Arai, R. \& Wu, H. 1997. Ag-NOR variation in chromosomes of Chinese bitterlings, Rhodeus tighti and Tanakia himantegus (Cypriniformes, Cyprinidae). Ichthyological Research, 44(3), 302-305.

Ueda, T., Naoi, H. \& Arai, R. 2001. Flexibility on the karyotype evolution in bitterlings (Pisces, Cyprinidae). Genetica, $111,423-432$.

Unal, S. \& Gaffaroğlu, M. 2016. Karyology of six cyprinid fishes from Seyhan and Ceyhan Rivers in Anatolia. Caryologia, 69(4), 362-369.

http://dx.doi.org/10.1080/00087114.2016.1247328. 